Gelanggang Olahraga: Jurnal Pendidikan Jasmani dan Olahraga

Volume 2, Nomor 1, Juli-Desember 2018

e-ISSN : 2597-6567

p-ISSN : 2614-607X

DOI : https://doi.org/10.31539/jpjo.v2i1.406

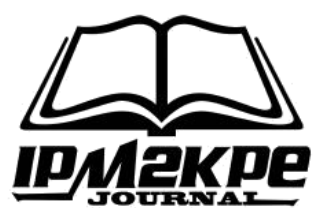

\title{
KETEPATAN SMASH PEMAIN BOLAVOLI SISWA SMA DITINJAU DARI KOORDINASI MATA-TANGAN DAN EXTENSI TOGOK
}

\author{
Ever Sovensi \\ STKIP-PGRI Lubuklinggau \\ ever_sovensi@yahoo.co.id
}

\begin{abstract}
ABSTRAK
Tujuan penelitian untuk mengetahui ketepatan smash pemain bola voli siswa ditinjau dari koordinasi mata-tangan dan extensi togok. Jenis penelitian ini adalah penelitian korelasional. Populasi penelitian ini seluruh pemain bola voli SMAN 2 Bengkulu Selatan sebanyak 15 Putri dan 30 Putra, sedangkan sampel diambil secara purposive sampling sehingga yang di ambil untuk penelitian hanya pemain putra saja dengan jumlah 30 orang. Tempat penelitian di lapangan bola voli SMAN 2 Bengkulu Selatan dan waktu penelitian pada bulan november 2011. Data koordinasi mata tangan diambil dengan tes Ball Warfen Und-fangen, extensi togok dengan Brige Up (Kayang), dan data Ketepatan Smash diambil dengan tes smash diagonal dan frontal. Teknik analisis data menggunakan teknik uji persyaratan analisis yaitu uji normalitas dan dilanjutkan dengan analisis korelasi sederhana dan korelasi ganda. Hasil analisis data menunjukkan bahwa, terdapat hubungan yang signifikan antara koordinasi mata tangan dan ekstensi togok secara bersama-sama dengan ketepatan smash pemain bola voli SMAN 2 Bengkulu Selatan.
\end{abstract}

Kata Kunci: Smash, Mata Tangan, Extensi Togok

\section{ABSTRACT}

The research objective was to determine the accuracy of volleyball players' smashes in terms of eye-hand coordination and EXTENSI TOGOK. This is correlation study. The population was all of the volleyball players in SMAN 2 South Bengkulu consist of 15 females and 30 males. Meanwhile, the sampling was purposive sample which was only all of the male players. The location of the study was volleyball field at SMAN2 South Bengkulu and conducted on november 2011. The data of hand-eye coordination was taken by using ball warfen und-fangen test, EXTENSI TOGOK by bridge up test and smash accuracy by diagonal and frontal smash test. The technique of data analysis used normality testing, simple correlation analysis and multiple correlation. It can be concluded that there was significant relationship between both hand-eye coordination and EXTENSI TOGOK and smash accuracy of volleyball players of SMAN 2 South Bengkulu.

Keyword: Smash, Hand Eyes, Extensi Togok 


\section{PENDAHULUAN}

Perkembangan Ilmu Pengetahuan dan Teknologi (IPTEK) saat ini membuat dunia olahraga pun ikut berkembang. Kemajuan IPTEK sangat berperan dalam melahirkan dan menumbuhkan serta kemantapan kecakapan-kecakapan motorik pada olahraga. Salah satu cabang olahraga yang ikut berkembang seiring dengan berkembangnya IPTEK yaitu bolavoli. Pada saat sekarang, olahraga bolavoli tidak saja hanya sebagai olahraga rekreasi tetapi sudah termasuk olahraga yang diharapkan untuk berprestasi dengan baik. Melalui olahraga prestasi diharapkan nantinya dapat melahirkan atlet yang handal.

Sesuai dengan Undang-undang Republik Indonesia Nomor 3 Tahun 2005 tentang Sistem Keolahragaan Nasional pasal 27 ayat 4 yaitu:"Pembinaan dan pengembangan olahraga prestasi dilaksanakan dengan memberdayakan perkumpulan olahraga, menumbuhkembangkan sentra pembinaan olahraga yang bersifat nasional dan daerah yang menyelenggarakan kompetisi secara berjenjang dan berkelanjutan". Sehubungan dengan undang-undang di atas, maka pembinaan prestasi dilaksanakan tidak hanya oleh lembaga-lembaga pemerintah, tetapi juga lembaga-lembaga swasta. Pembinaan dilakukan dengan berjenjang dan terusmenerus, sehingga dapat dicapai prestasi yang maksimal melalui pertandinganpertandingan yang diikuti.

Permainan bolavoli memiliki teknik-teknik dasar yaitu: servis, passing, smash dan block, dimana dalam permainan bolavoli kemenangan sangat bergantung pada teknik, fisik, taktik dan mental seorang pemain. Keempat unsur tersebut merupakan unsur-unsur prestasi yang harus dimiliki. Smash merupakan salah satu contoh teknik dasar permainan bolavoli. Bachtiar (1999) mengatakan smash adalah "pukulan yang utama dalam melakukan penyerangan ke daerah lawan". Smash merupakan modal untuk mendapatkan angka. Dari pendapat di atas maka dengan teknik smash yang baik maka pertahanan lawan dapat dimatikan dan kemenangan dapat diraih. Dalam teknik smash kondisi fisik merupakan faktor yang dapat mempengaruhi keberhasilan smash.

Menurut Sajoto (1992) ada sepuluh komponen kondisi fisik yaitu: kekuatan (strength) 2) daya tahan (endurance) a) daya tahan umum (General Endurance) b) daya tahan Otot (muscle Endurance) 3) daya ledak otot (muscular power) Kecepatan (Speed) 5) daya lentuk (flexibility) 6) Koordinasi (Coordination) 7) keseimbangan (Balance) 8) ketepatan (accuracy) 9) reaksi (reaction) 10) kesetimbangan (body composition).

Bardasarkan pendapat di atas koordinasi dan daya lentuk merupakan beberapa komponen kondisi fisik yang sangat penting dalam melakukan smash. Dalam teknik Smash koordinasi merupakan komponen yang sangat berperan dalam melakukan smash, terutama koordinasi mata-tangan, karena dengan koordinasi yang baik antara mata dan tangan maka ketepatan pukulan smash akan semakin baik. Selanjutnya kelentukan juga sangat berperan untuk menambah power saat memukul bola ketika melakukan smash, sehingga laju bola menjadi lebih cepat dan keras sehingga dapat menyulitkan pemain lawan untuk mengantisipasi bola.

Pantauan peneliti dari fenomena yang terjadi di lapangan, diduga ketepatan smash pemain bolavoli SMAN 2 Bengkulu Selatan masih rendah, ini terbukti pada saat pertandingan pukulan smash yang dihasilkan masih lemah dan kurang terarah sehinggah mudah diblock oleh lawan. Hal ini kemungkinan disebabkan 
karena masih rendahnya koordinasi mata-tangan dan kelentukan pemain bolavoli SMAN 2 Bengkulu Selatan. Hal ini menyebabkan kualitas smash menurun dan juga mengakibatkan pukulan smash yang dihasilkan masih belum keras dan masih jauh dari yang diharapkan. Pada saat melakukan smash penempatan-penempatan bola pada posisi yang kosong tidak terlaksana dengan baik.

Melihat perkembangan permainan pada tiap-tiap pertandingan sering terjadi kegagalan dalam melakukan serangan, terutama pada saat melakukan smash ke daerah lawan. Diantara kesalahan itu berupa kurangnya ketepatan smash, sehingga smash yang dihasilkan kurang keras dan tidak terarah. Hal ini diakibatkan karena rendahnya kondisi fisik yang dimiliki pemain, diantaranya yaitu koordinasi mata-tangan dan kelentukan pemain bolavoli SMAN 2 Bengkulu Selatan.

\section{KAJIAN TEORI}

Kusyanto (1999) mengatakan bahwa bolavoli adalah permainan yang dilakukan oleh dua regu, yang masing-masing terdiri dari enam orang. Selanjutnya Mukholid (2004) menyatakan bahwa permainan bolavoli adalah suatu permainan yang menggunakan bola untuk divolley (dipantulkan) di udara hilir mudik di atas net (jaring) dengan maksud dapat menjatuhkan bola di dalam petak daerah lapangan lawan, dalam rangka mencari kemenangan. Memvolley atau memantulkan bola ke udara dapat mempergunakan seluruh anggota atau bagian tubuh dari ujung kaki sampai ke kepala dengan pantulan sempurna."

Menurut Bachtiar (1999) ide dasar permainan bolavoli itu adalah memasukkan bola ke daerah lawan melewati suatu rintangan berupa tali atau net. Kemudian untuk memenangkan (memainkan) bola di udara sebelum bola jatuh atau bola menyentuh lantai. Selanjutnya menurut PB. PBVSI dalam Kartono (2006) menyatakan bahwa perhitungan perolehan angka dalam permainan bolavoli menggunakan sistim reli. Tim yang memenangkan sebuah reli akan mendapat satu angka (relly point system). Apabila tim yang sedang menerima servis memenangkan reli akan mendapat satu angka dan berhak melakukan servis berikutnya, serta pemain lainnya melakukan pegeseran satu posisi searah jarum jam.

Sesuai dari ide permainan bolavoli, agar dapat bermain bolavoli dengan baik, seorang pemain harus dapat menguasai teknik dasar permainan bolavoli. Teknik dasar permainan bolavoli harus benar-benar dikuasai terlebih dahulu agar dapat mengembangkan mutu prestasi permainan bolavoli. Penguasaan teknik dasar permainan bolavoli merupakan salah satu unsur yang dapat menentukan menang atau kalahnya tim dalam suatu permainan bolavoli. Adapun teknik dasar permainan bolavoli menurut Mukholid (2004) terdiri dari beberapa bagian, diantaranya; servis, passing, smash dan block.

Menurut Bachtiar (1999) smash adalah pukulan yang utama dalam penyerangan untuk mencapai kemenangan. Dalam melakukan smash raihan dan melompat yang tinggi agar keberhasilan dapat dicapai dengan gemilang Dari kutipan di atas smash merupakan pukulan yang keras serta dapat mematikan bola pada daerah lawan dan merupakan pukulan yang sangat menguntungkan bagi pemain yang memiliki raihan serta kemampuan melompat yang tinggi.

Selanjutnya menurut Erianti (2004) macam-macam smash menurut umpan antara lain; (1) smash normal (open Smash), (2) smash semi, (3) smash pull, (4) 
smash pull jalan, (5) smash langsung, (6) smash dari belakang, (7) smash silang dan smash lurus, (8) smash cekis (drive smash, (9) smash pull straiight". Adapun proses pelaksanaan melakukan smash menurut Mukholid (2004 : 38-39)"berikut; (1) Sikap permulaan. Berdiri dengan sikap siap normal dengan jarak 3 sampai 4 meter dari jaring (net). Pada saat mengadakan langkah ke depan terlebih dahulu melakukan langka-langka kecil ditempat, (2) gerak pelaksanaan; (a) melangkah kecil ke depan, kemudian menumpu dengan kedua kaki disertai dengan gerakan merendahkan badan dengan cara menekuk lutut, (b) kedua lengan sudah berada disamping belakang badan. Diikuti dengan tolakan kaki ke atas secara eksplosife dan dibantu dengan ayunan kedua lengan dari arah belakang ke depan atas, (c) kaki kiri dilangkahkan ke depan perlahan, diikuti dengan langkah kaki disamping kaki kanan agak sedikit ke depan, (d) kedua lengan diletakan dibelakang badan, bersamaan dengan gerakan merendahkan badan dengan cara menekuk lutut agak rendah, selanjutnya segera melakukan tolakan sambil mengayunkan lengan kedepan atas, $€$ pada saat lompatan tinggi, tangan segera meraih dan memukul bola sekeras-kerasnya di atas jarring, (3) gerak lanjutan. Setelah bola berhasil di pukul, keseimbangan badan harus dijaga agar anggota badan tidak menyentuh net”.

Untuk mencapai teknik smash yang baik dan menghasilkan poin, maka pemain harus memiliki koordinasi, kelentukan, kekuatan, dan daya ledak sehingga memiliki raihan yang tinggi, sehingga dapat melakukan smash yang terarah dan tajam. Hal ini sejalan dengan pendapat Bachtiar (1999) yang menyatakan "Apabila kemampuan koordinasi seseorang pemain bola voli bagus, maka gerakan yang dihasilkan akan efektif dan efisien, sebaliknya apabila kemampuan koordinasi kurang bagus maka hasilnya tidak sesuai dengan yang diharapkan".

Menurut pendapat Syafruddin (2004) bahwa koordinasi merupakan kemampuan untuk menyelesaikan tugas-tugas motorik secara cepat dan terarah yang ditentukan oleh proses pengendalian dan pengaturan gerakan serta kerjasama system persyarafan pusat. Selanjutnya Kiram (1999) mengatakan "koordinasi merupakan timbal balik antara susunan syaraf pusat dengan alat gerak dalam mengatur dan mengendalikan impuls dan kerja otot untuk pelaksanaan suatu gerakan".

Dari beberapa pendapat para ahli tersebut dapat disimpulkan bahwa koordinasi merupakan hubungan kerjasama antara susunan syaraf pusat dengan alat gerak saat berkontraksi dalam menyelesaikan tugas-tugas motorik secara cepat dan terarah. Dalam setiap aktivitas olahraga kemampuan koordinasi sangat menentukan keberhasilan dalam menyelesaikan tugas-tugas motorik sesuai tuntutan cabang olahraga tersebut. Dalam bola voli misalnya kemampuan koordinasi kaki, tangan, dan mata berperan aktif dalam melakukan service, pasing, smash, dan block.

Menurut Bachtiar (1999) apabila kemampuan koordinasi seseorang pemain bola voli bagus, maka gerakan yang dihasilkan akan efektif dan efisien, sebaliknya apabila kemampuan koordinasi kurang bagus maka hasilnya tidak sesuai dengan yang diharapkan. Baik tidaknya kemampuan koordinasi seseorang ditentukan oleh banyak faktor seperti : kemampuan intelegensi, ketepatan organ sensorik, pengalaman motorik dan tingkat kemampuan biomotor. Namun demikian kemampuan seseorang dapat ditingkatkan dengan melakukan latihanlatihan yang dapat merangsang kerja syaraf otot dan alat indra. 
Dari uraian diatas dapat dijelaskan bahwa koordinasi berperan sekali dalam setiap aktifitas olahraga baik itu koordinasi gerakan maupun koordinasi antara anggota tubuh. Koordinasi gerakan merupakan kemampuan seseorang dalam melakukan tugas seperti : service, passing, smash, dan block dalam permainan bola voli, mulai dari fase awal, fase utama sampai pada fase akhir. Sedangkan koordinasi antara anggota tubuh yaitu seperti koordinasi mata tangan.

Selain koordinasi di atas, kelentukan juga sangat berperan penting dalam keberhasilan smash. Hal ini didukung pendapat Syafruddin (2004) kelenturan adalah salah satu unsur fisik yang menentukan dalam mempelajari keterampilanketerampilan gerakan, mencegah cedera, dan mengembangkan kemampuan kekuatan, kecepatan, daya tahan dan koordinasi. Selain itu menurut Sajoto (1992) menyatakan pula kelenturan adalah keefektifan seseorang dalam penyesuaian dirinya untuk melakukan segala aktifitas tubuh, pengukuran seluas-luasnya terutama otot-otot, ligamen dan disekitar persendian.

Syafruddin (2004) kelentukan khusus merupakan kelentukan yang dominan dibutuhkan dalam suatu cabang olahraga tertentu. Cabang olahraga yang dimaksudkan adalah permainan bolavoli. Pada olahraga permainan bolavoli, kelentukan togok sangat dibutuhkan pada saat melakukan smash sehingga menghasilkan hasil smash yang baik dalam kategori tanding. Togok/tulang belakang (kolumna vertebralis) terdiri dari empat bagian Vertebra servikalis, vertebra torakalis, vertebra lumbalis dan vertebra sakralis yang berfungsi sebagai penopang badan yang kokoh dan memberi extensitas memungkinkan membengkok tanpa patah.

Harsono (1988) menyatakan bahwa lentuk tidaknya seseorang ditentukan luas atau sempitnya ruang gerak sendi-sendinya. Jadi kelentukan adalah kemampuan melakukan gerakan dalam ruang gerak sendi. Kecuali oleh ruang gerak sendi, kelentukan juga ditentukan elastisitas tidaknya otot-otot, tendon, dan ligamen. Kelentukan sangat berguna untuk mencegah terjadinya cidera. Dengan dimilikinya kelentukan oleh seseorang akan dapat: 1) mengurangi kemungkinan terjadinya cidera otot dan sendi, 2) membantu dalam mengembangkan kecepatan, koordinasi dan kelincahan, 3) membantu memperkembang prestasi, 4) menghemat pengeluaran tenaga (efisien) pada waktu melakukan gerakan-gerakan, dan 5) membantu memperbaiki sikap tubuh.

Togok/tulang belakang (kolumna vertebralis) terdiri dari empat bagian Vertebra servikalis, vertebra torakalis, vertebra lumbalis dan vertebra sakralis yang berfungsi sebagai penopang badan yang kokoh dan memberi extensitas memungkinkan membengkok tanpa patah (Syaifuddin, 2004).

Adapun faktor-faktor yang mempengaruhi kelentukan seperti yang dikemukakan oleh Syafruddin (2004) antara lain: (1) koordinasi otot synergis dan antagonis, (2) bentuk persendian, (3) temperatur otot, (4) kemampuan tendon dan ligament, (5) kemampuan proses pengendalian fisiologi persyarafan, (6) usia dan jenis kelamin.”. Dengan demikian jelas bahwa kelentukan memegang peranan yang sangat besar dalam mempelajari keterampilan gerak dan dalam mengoptimalkan kemampuan fisik yang lain. Bahkan untuk mengembangkan kemampuan kecepatan dan kelincahan dibutuhkan unsur kelentukan agar dapat menentukan keberhasilannya. Dengan kata lain tanpa kelentukan, kecepatan tidak akan berkembang secara optimal. 
Untuk meningkatkan kelentukan togok dapat dilakukan dalam bentuk latihan yang sudah terprogram dan berkesinambungan seperti latihan peregangan dinamis dengan latihan melakukan gerakan extensi sambil memutar bahu dan latihan peregangan statis dengan cara penguluran otot dalam sendi sejauh mungki.

\section{METODE PENELITIAN}

Penelitian ini tergolong penelitian Korelasional, yang ingin melihat hubungan antara variabel bebas dengan variabel terikat, adapun variabel bebasnya adalah koordinasi mata-tangan (X1) dan kelentukan togok (X2) sedangkan variabel terikatnya adalah ketepatan Smash (Y). Penelitian ini dilaksanakan di lapangan bola voli SMAN 2 Bengkulu Selatan pada Juli 2011.

Populasi dalam penelitian ini adalah seluruh pemain bola voli SMAN 2 Bengkulu Selatan yang terdiri dari 15 pemain putri dan 30 pemain putra yang aktif berlatih di SMA Negeri 2 Bengkulu Selatan tahun 2011. Teknik penarikan sampel pada penelitian ini menggunakan teknik purposive sampling. Karena pertimbangan ada perbedaan kemampuan secara fisik antara pemain putra dan putri dan pertimbangan pemain putri tidak aktif mengikuti latihan. Maka sampel yang diambil dalam penelitian ini adalah pemain putra yang aktif dalam latihan saja yang berjumlah 30 orang pemain.

Jenis data yang digunakan dalam penelitian ini adalah data primer, yang diambil langsung dari hasil tes yang dilakukan pemain bola voli SMAN 2 Bengkulu Selatan. Data yang diperlukan dalam penelitian ini berasal dari tes koordinasi mata-tangan, tes kelentukan togok dan tes ketepatan Smash pemain bola voli SMAN 2 Bengkulu Selatan yang dijadikan sampel. Teknik pengambilan data yang digunakan dalam penelitian ini adalah test kordinasi mata-tangan yaitu Ball Warfen Und-fangen dalam M. Furqon H (2006) Tes kelentukan togok dengan kayang Bridge-Up test (Ismaryati, 2006: 108) dan test ketepatan smash yaitu tes smash diagonal dan frontal (Syafruddin 2004).

\section{Instrument Penelitian}

\section{Tes Koordinasi Mata - Tangan}

Test kemampuan koordinasi mata-tangan yang dilakukan dalam penelitian ini adalah test Ball Warfen Und-fangen dalam M. Furqon H (2006) adalah sebagai berikut :

1. Tujuan untuk mengukur koordinasi mata-tangan.

2. Alat. Bola tenis, dinding tempat sasaran pantulan, kapur, stopwatch., meteran, blangko penelitian, dan alat tulis.

3. Pelaksanaan :

a. Pemain tegak lurus menghadap dinding sasaran dengan jarak yang telah ditentukan dengan memegang bola di tangan.

b. Setelah aba-aba "ya" pemain melakukan pantulan kedinding sasaran, kemudian menangkapnya kembali setelah bola memantul.

c. Pemain malakukan pantulan ke dinding sasaran dalam waktu 15 detik dengan setiap pemain melakukan dua kali percobaan.

d. Saat melakukan pantulan ke dinding sasaran, bola tidak boleh keluar dari batas dinding sasaran, jika terjadi maka dinyatakan gagal.

Nilai yang di dapat oleh pemain, diperoleh dari banyaknya pantulan yang sah dalam waktu 15 detik. 


\section{Tes Kelentukan togok}

Tes kelentukan dengan kayang (Bridge-Up test) Ismaryati, (2006).

\begin{tabular}{|c|c|}
\hline a. Tujuan & $\begin{array}{l}\text { : Untuk mengukur kelentukan otot Punggung ke arah belakang } \\
\text { (ekstensi). }\end{array}$ \\
\hline b. Tingkat umur & Laki-laki dan perempuan berusia 6 tahun ke atas. \\
\hline c. Perlengkapan & $\begin{array}{l}\text { Lantai yang datar sebaiknya indoor dapat menggunakan matras } \\
\text { atau karpet dan pita pengukur atau Penggaris. }\end{array}$ \\
\hline h. Pelaksanaan & $\begin{array}{l}\text { Testee berdiri di lantai, dan menempatkan jari-jari di depan } \\
\text { dinding, beri tanda garis bekas tumit. } \\
\text { Lakukan gerakan kayang, telapak kaki tetap menempel di lantai. } \\
\text { Dengan posisi kayang, dekatkan jari-jari tangan ke tumit, beri } \\
\text { tanda pada ujung jari tangan yang paling dekat dengan } \\
\text { tumit. } \\
\text { Lakukan gerakan ini tiga kali. }\end{array}$ \\
\hline $\begin{array}{l}\text { i. Penilaian } \\
\text { (scoring) }\end{array}$ & $\begin{array}{l}\text { jarak yang terdekat antara ujung jari tangan dan tumit } \\
\text { merupakan nilai kelentukan testee. }\end{array}$ \\
\hline
\end{tabular}

\section{Tes Kemampuan Ketepatan Smash}

Untuk mengukur ketepatan smash dilakukan tes smash diagonal dan frontal (Syafruddin, 2004. Smash yang diambil pada penelitian ini adalah smash normal (open smash) proses smash dimulai dari sikap permulaan, gerakan pelaksanaan dan gerakan lanjutan sama dengan proses pelaksanaan smash secara umum. Penjelasan tes :lambungkan (umpan) bola cukup tinggi mencapai 3 meter ke atas dan jarak lintasan bola yang diumpankan berkisar antara 20 sampai $50 \mathrm{~cm}$ dari net, langkah awal dimulai setelah lepas dari tangan pengumpan dengan pandangan berkonsentrasi kepada jalanya bola, meraih dan memukul bola setinggi-tingginya di atas net, teste memukul bola yang dilambungkan dari posisi III ke posisi IV secara diagonal dan frontal. Pada sudut belakang lapangan terdapat dua buah matras senam dengan jarak $0,5 \mathrm{~m}$ dari garis belakang dan $0,5 \mathrm{~m}$ dari garis samping. Pemain melakukan smash berturut-turut 15 kali secara diagonal dan 15 secara frontal. Setelah 30 kali smash jumlah sentuhan di jumlahkan.

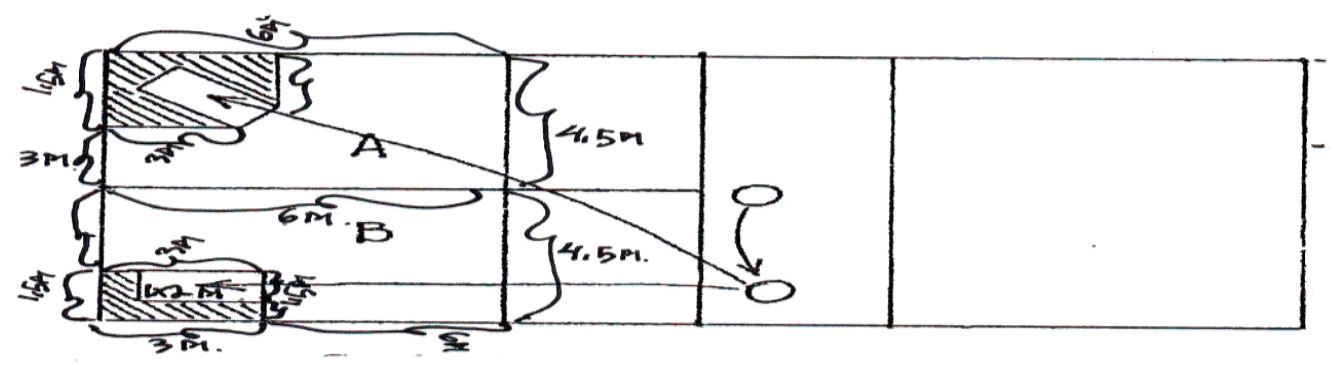

Gambar 1. Bentuk Tes Ketepatan Smash (Syafruddin 2004)

Penilaian : Masuk diatas Matras nilai

Masuk dalam petak bergaris nilai

Masuk dalam petak A dan B
$=4$ poin

$=3$ poin

$=2$ poin 


\section{HASIL PENELITIAN}

\section{Hubungan antara Koordinasi Mata Tangan dengan Ketepatan smash}

Analisis korelasi terhadap Koordinasi Mata Tangan dengan Ketepatan smash menghasilkan koefisien korelasi sebesar $\mathrm{r}_{\mathrm{yl}}=0,476$, dan koefisisen determinasi $\mathrm{r}^{2}$ $=0,227$. Untuk lebih jelasnya dapat dilihat rangkuman hasil analisis Tabel 2 berikut ini.

Tabel 1

Rangkuman Hasil Analisis Korelasi antara Variabel Koordinasi Mata Tangan(X1) dan Ketepatan smash (Y)

\begin{tabular}{ccccr}
\hline Korelasi Antara & Koefisien Korelasi (r) & Koefisien Determinasi $\left(\mathrm{r}^{2}\right)$ & t-hitung & $\begin{array}{c}\text { t-tabel } \\
\alpha \square=0,05\end{array}$ \\
\hline $\mathrm{X}_{1}$ dan $\mathrm{Y}$ & 0,476 & 0,227 & 2,868 & 1,701
\end{tabular}

Keterangan:

Koefisien korelasi signifikan $\left(t_{\text {hit }}=2,868>t_{\text {tab }}=1,701\right)$

Berdasarkan uji keberartian korelasi antara pasangan skor Koordinasi Mata Tangan $\left(\mathrm{X}_{1}\right)$ dengan Ketepatan smash $(\mathrm{Y})$ sebagaimana terlihat pada Tabel 7 di atas diperoleh $t_{\text {hit }}=2,868>t_{\text {tab }}=1,701$ pada taraf signifikansi $\alpha \square=0,05$. Dengan demikian, Ha yang mengatakan Terdapat hubungan antara Koordinasi Mata Tangan dengan Ketepatan smash diterima, konsekuensinya H0 ditolak. Temuan ini menyimpulkan bahwa Terdapat hubungan antara Koordinasi Mata Tangan dengan Ketepatan smash. Hal ini berarti semakin baik Koordinasi Mata Tangan seseorang, maka semakin baik pula Ketepatan smash

\section{Hubungan antara extensi togok dengan Ketepatan smash}

Analisis korelasi antara kelentukan togok dengan Ketepatan menghasilkan koefisien korelasi sebesar $r_{\mathrm{y} 2}=0,451$, dan koefisisen determinasi $\mathrm{r}^{2}=0,203$. Untuk lebih jelasnya dapat dilihat rangkuman hasil analisis Tabel 3 berikut ini.

Tabel 2

Rangkuman Hasil Analisis Korelasi antara Kelentukan Togok dengan Ketepatan smash

\begin{tabular}{ccccrc}
\hline Korelasi Antara & $\begin{array}{l}\text { Koefisien } \\
(\mathrm{r})\end{array}$ & Korelasi & Koefisien Determinasi $\left(\mathrm{r}^{2}\right)$ & t-hitung & $\begin{array}{l}\text { t-tabel } \\
\alpha \square=0,05\end{array}$ \\
\hline $\mathrm{X}_{2}$ dan $\mathrm{Y}$ & 0,451 & 0,203 & 2,674 & 1,701
\end{tabular}

\section{Keterangan:}

Koefisien korelasi signifikan $\left(t_{\text {hit }}=2,674>t_{\text {tab }}=1,701\right)$

Berdasarkan uji keberartian korelasi antara pasangan skor Kelentukan togok $\left(\mathrm{X}_{2}\right)$ dengan Ketepatan smash $(\mathrm{Y})$ sebagaimana terlihat pada Tabel 8 diperoleh $\mathrm{t}_{\text {hitung }}$ $=2,674>\mathrm{t}_{\mathrm{tab}}=1,701$ pada taraf signifikansi $\alpha=0,05$. Dengan demikian, Ha yang mengatakan bahwa Terdapat hubungan yang signifikan antara kelentukan togok dengan Ketepatan smash diterima, konsekuensinya HO ditolak. Temuan ini menyimpulkan bahwa semakin tinggi skor kelentukan togok, maka semakin tinggi pula kemampuan Ketepatan smash. 


\section{Hubungan antara Koordinasi Mata Tangan dan Extensi Togok secara bersama-sama dengan Ketepatan Smash}

Analisis korelasi terhadap Koordinasi Mata Tangan dan ekstensi togok secara bersama-sama dengan Ketepatan smash menghasilkan korelasi ganda sebesar 0,652. Untuk uji keberartian koefisien korelasi disajikan pada tabel 4 berikut ini.

Tabel 3

Rangkuman Hasil Analisis Korelasi Ganda antara Koordinasi Mata Tangan dan Kelentukan Togok secara bersama-sama dengan Ketepatan Smash

\begin{tabular}{lccrc}
\hline Korelasi Antara & $\begin{array}{c}\text { Koefisien } \\
\text { Korelasi (R) }\end{array}$ & $\begin{array}{l}\text { Koefisien } \\
\text { Determinasi }\left(\mathrm{R}^{2}\right)\end{array}$ & F-hitung & $\begin{array}{c}\text { F-tabel } \\
\alpha \square=0,05\end{array}$ \\
\hline $\mathrm{X}_{1}$ dan $\mathrm{X}_{2}$ dengan $\mathrm{Y}$ & 0,652 & 0,425 & 9,983 & 3,35 \\
\hline
\end{tabular}

Keterangan:

regresi signifikan $\left(F_{h}=9,983>F_{t}=3,35\right)$.

Sebagaimana terlihat pada tabel 3 di atas berdasarkan hasil perhitungan diperoleh koefisien korelasi didapat hasil $\mathrm{R}=0,652$, determinansi $\mathrm{R}^{2}$ sebesar 0,425 , dan $F_{\text {hitung }}=9,983>F_{\text {tabel }}=3,35$ pada taraf signifikansi $\alpha=0,05$. Dapat disimpulkan, bahwa koefisien korelasi ganda yang diperoleh dalam penelitian ini signifikan. Temuan ini menerima $\mathrm{H}_{\mathrm{a}}$, yakni Terdapat hubungan yang signifikan antara Koordinasi Mata Tangan dan kelentukan togok secara bersama-sama dengan Ketepatan smash. Konsekuensinya $\mathrm{H}_{0}$ ditolak. Berdasarkan hasil pengujian ketiga hipotesis di atas, maka dapat dirangkum hasil penelitian dalam bentuk bagan "Hubungan Koordinasi Mata-Tangan dan exstensi togok dengan Ketepatan smash" seperti di gambar bawah ini :

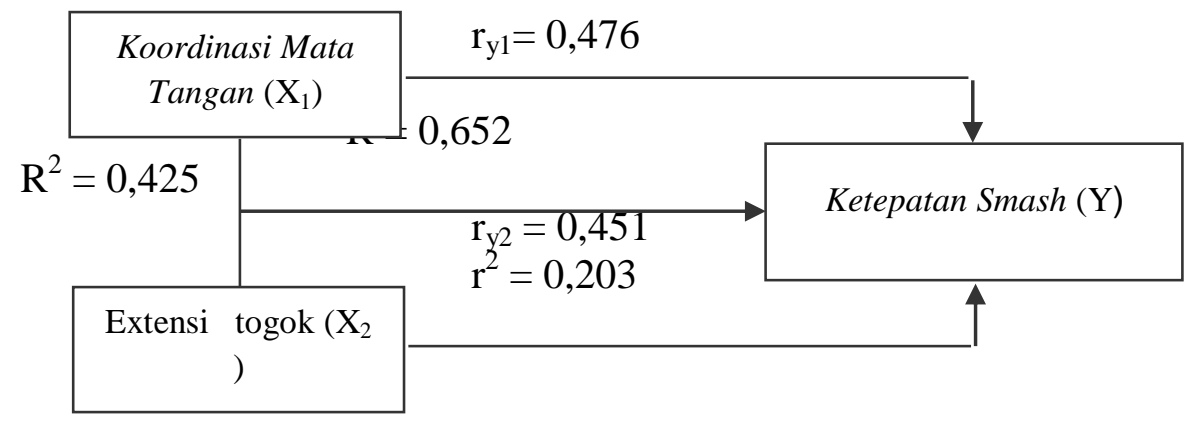

Terdapatnya hubungan Koordinasi Mata-Tangan dan extensi togok dengan Ketepatan smash dapat memberi arti bahwa tinggi rendahnya Kemampuan Ketepatan smash sangat ditentukan oleh tinggi rendahnya Koordinasi MataTangan dan extensi togok. Dengan demikian untuk meningkatkan Kemampuan Ketepatan smash memerlukan Koordinasi Mata Tangan dan extensi togok yang baik.

\section{PEMBAHASAN}

Dari hasil analisis korelasi terhadap Koordinasi Mata Tangan dengan Ketepatan smash menghasilkan koefisien korelasi sebesar $r_{\mathrm{y} 1}=0,476$, dan koefisisen determinasi $r^{2}=0,227$, dengan $t_{\text {hitung }}=2,868>t_{\text {tabel }}=1,701$, dapat diambil kesimpulan bahwa terdapat hubungan yang signifikan antara Koordinasi MataTangan dengan Ketepatan smash. Koordinasi Mata Tangan yang dimiliki sampel juga akan lebih baik dengan adanya latihan sehingga dengan proses latihan diharapkan 
Koordinasi Mata-Tangan semakin meningkat dan memberi pengaruh yang besar terhadap Ketepatan smash. Temuan ini diperkuat dengan pendapat Bachtiar (1999) apabila kemampuan koordinasi seseorang pemain bola voli bagus, maka gerakan yang dihasilkan akan efektif dan efisien, sebaliknya apabila kemampuan koordinasi kurang bagus maka hasilnya tidak sesuai dengan yang diharapkan.

Dari hasil analisis korelasi extensi togok dengan Ketepatan smash menghasilkan koefisien korelasi sebesar $r_{\mathrm{yl}}=0,451$, dan koefisisen determinasi $\mathrm{r}^{2}$ $=0,203$, dengan $t_{\text {hitung }}=2,674>t_{\text {tabel }}=1,701$, kelentukan togok yang dimiliki sampel juga akan lebih baik dengan adanya latihan sehingga dengan proses latihan diharapkan kelentukan semakin meningkat dan memberikan sumbangan besar terhadap kemampuan Ketepatan smash. Sesuai dengan batasan kelentukan togok sebagaimana diterangkan diatas, kelentukan togok dapat dikembangkan melalui latihan-latihan peregangan otot dan latihan-latihan memperluas ruang gerak sendisendi. Menurut Harsono (1988) ada beberapa metode latihan peregangan yang dapat dipakai untuk mengembangkan kelentukan yaitu; 1) peregangan dinamis, 2) peregangan statis, 3) peregangan pasif, 4) peregangan PNF atau peregangan kontraksi-rileksasi.

Berpedoman pada kutipan di atas, jelas bahwa tingkat kelentukan togok tergantung pada ruang gerak persendian dan otot-otot, kelentukan merupakan kemampuan otot meregang dengan ruang gerak yang jauh tanpa menimbulkan rasa sakit. Syafruddin (2004) Kelentukan khusus merupakan kelentukan yang dominan dibutuhkan dalam suatu cabang olahraga tertentu. Cabang olahraga yang dimaksudkan adalah olahraga permainan bolavoli. Pada olahraga permainan bolavoli, kelentukan sangat dibutuhkan pada saat melakukan passing bawah dan atas, smash, blocking, sehingga terlihat keindahan dari gerakan yang ditampilkan dan mempunyai kualitas yang baik dalam kategori tanding.

Untuk mengetahui hubungan dari dua variabel atau lebih digunakan rumus korelasi ganda. Kriteria pengujian signifikan dengan uji $\mathrm{F}$. Jika $F_{\text {hitung }}>F_{\text {tabel }}$ maka terdapat hubungan dan sebaliknya tidak terdapat hubungan jika $F_{\text {hitung }}<$ $\mathrm{F}_{\text {tabel. }}$. Dari hasil perhitungan diperoleh koefisien korelasi ganda (uji $\mathrm{F}$ ) didapat $F_{\text {hitung }}=9,983$, sedangkan $F_{\text {tabel }}$ diperoleh sebesar 3,5. Jadi $F_{\text {hitung }}>F_{\text {tabel }}$, selanjutnya hasil perhitungan $\mathrm{R}$ (korelasi berganda) secara bersama-sama tingkat kontribusi Koordinasi Mata Tangan $\left(\mathrm{X}_{1}\right)$ dan Kelentukan togok $\left(\mathrm{X}_{2}\right)$ terhadap Ketepatan smash (Y) sebesar 0,652.

Dilihat dari analisis data yang dilakukan maka Koordinasi Mata Tangan dan kelentukan togok dengan kemampuan ketepatan smash juga terdapat hubungan yang signifikan, karena dengan adanya latihan yang dilakukan sampel sehingga Koordinasi Mata Tangan dan kelentukan togok semakin baik. Ketepatan smash pula tergantung pada Koordinasi Mata Tangan dan kelentukan togok, semakin baik Koordinasi Mata Tangan maka semakin bagus ketepatan smash, begitu juga dengan kelentukan togok, semakin baik tingkat kelentukan togok yang dimiliki maka bagus pula ketepatan smash.

Semua cabang olahraga yang memerlukan waktu yang relatif lama pada dasarnya memerlukan kelentukan dan Koordinasi Mata Tangan, apabila pada cabang bolavoli yang sangat membutuhkan kondisi fisik yang maksimal terutama pada kondisi fisik yang sangat dibutuhkan kondisi fisik yang maksimal terutama pada kondisi fisik yang sangat dibutuhkan antara lain Koordinasi Mata Tangan dan kelentukan togok untuk mendapatkan kemampuan yang maksimal dibutuhkan 
latihan yang maksimal dan kontinu. Menurut Let Zelter dalam Syafruddin (2004), ada 3 tujuan latihan olahraga yaitu: "1.Latihan olahraga dapat memperbaiki kemampuan dibidang fisik, psikis dan sosial, 2. latihan olahraga bertujuan untuk menstabilkan kemampuan dibidang fisik, psikis dan sosial, 3. latihan olahraga berusaha menghindari terjadinya penurunan kemampuan fisik, psikis dan kualitas moral". Begitu juga halnya dengan kemampuan seseorang dalam melakukan Smash, ketepatan smash dapat ditingkatkan melalui latihan, sehingga dengan latihan terprogram dapat menghasilkan ketepatan smash yang optimal.

\section{SIMPULAN}

Terdapat hubungan yang signifikan antara koordinasi mata-tangan dengan ketepatan smash Pemain Bolavoli SMAN 2 Bengkulu Selatan. Terdapat hubungan yang signifikan antara koordinasi mata-tangan dengan ketepatan smash. Terdapat hubungan yang signifikan antara koordinasi mata-tangan dan kelentukan togok secara bersama-sama dengan ketepatan smash

\section{DAFTAR PUSTAKA}

Undang-Undang Negara Ripublik Indonesia Nomor. 3, 2005. Sistem Keolahragaan Nasional. Jakarta : Menpora.

Bactiar, (1999). Pengetahuan Dasar-Dasar Permainan Bolavoli. Padang : FIK UNP.

Sajoto M, (1992). Peningkatan dan Pembinaan Kekuatan Kondisi Fisik Dalam Olahraga. Semarang : Effhar dan Dahara Prize.

Kusyanto, Y. (1999). Penuntun Belajar Pendidikan Jasmani dan Kesehatan I (Berdasarkan Kurikulum Baru GBPP 1994). Bandung : Ganeca Exact Bandung.

Mukholid, (2004). Pendidikan Jasmani Kelas I SMA (Kurikulum Berbasis Kompetensi 2004). Surakarta : Yudistira.

Erianti, (2004). Buku Ajar Bola Voli. Padang : FIK UNP

Kartono, E. (2006). Panduan Materi Pendidikan Jasmani. Solo: Gita Kencana.

Kiram, Y. (1999). Belajar Motorik. Padang : FIK UNP.

Harsono, (1988). Ilmu Coaching. Jakarta : Pusat Ilmu Olahraga, KONI Pusat.

Syafruddin, (1999). Dasar-Dasar Kepelatihan Olahraga. Padang : FIK UNP.

Syafruddin, (2004). Permainan Bolavoli (Training-Teknik-Taktik). Terjemahan. Padang : FIK-UNP.

Ismaryati, (2006). Tes dan Pengukuran Olahraga. Cetakan Pertama. Surakarta : UNS. 